\title{
A dinuclear cobalt(II) complex of calix[8]arenes exibiting strong magnetic anisotropy $\dagger+$
}

\author{
Sarah Petit, ${ }^{a}$ Guillaume Pilet, ${ }^{a}$ Dominique Luneau, ${ }^{* a}$ Liviu F. Chibotaru ${ }^{b}$ and Liviu Ungur ${ }^{b}$ \\ Received 13th June 2007, Accepted 1st August 2007 \\ First published as an Advance Article on the web 15th August 2007 \\ DOI: $10.1039 / \mathrm{b} 708926 \mathrm{k}$
}

The solvothermal reaction of cobalt(II) acetate with $p$-tert-butylcalix[8]arene (calix) and triethylamine affords the compound $\left(\mathrm{Et}_{3} \mathrm{NH}\right)_{2}\left[\mathrm{Co}_{2}{ }_{2}(\mathrm{calix})_{2}\right]\left(1 \cdot 2 \mathrm{Et}_{3} \mathrm{NH}\right)$ that shows a hydrogen bond bridged dinuclear complex $\left[\mathrm{Co}_{2}{ }_{2}(\mathrm{calix})_{2}\right]^{2-}$ (1) with cobalt(II) ions in a tetrahedral geometry. The compound crystallises in the monoclinic, space group $P 2_{1} / n$ with cell parameters $a=14.89(1) \AA, b=20.90(2) \AA$, $c=30.87(4) \AA, \beta=102.57(7)^{\circ}, V=9376(16) \AA^{3}, Z=2$. The magnetic studies together with ab initio calculations are evidence of an important role of the geometry of the second coordination sphere of carbon and hydrogen atoms around the $\mathrm{CoO}_{4}$ core in quantifying the zero field splitting on cobalt sites. This results in strong magnetic anisotropies with a negative axial component on the cobalt fragments.

\section{Introduction}

We are interested in polynuclear complexes ${ }^{1}$ with high magnetic spin and anisotropy that may exhibit single-molecule magnets (SMMs) behavior. ${ }^{2-5}$ From the chemical point of view this is not an easy task as one requirement is the synthesis of high nuclearity complexes well isolated from each other. The general approach is to use multidentate and bulky ligands that favour the metal aggregation then keeping the resulting clusters aside from each other by lying at the periphery. ${ }^{6}$ To this purpose, calixarenes $^{7}$ look particularly attractive. Indeed they are bulky and sizeable macrocycles equipped with phenol oxygen atoms that are available for coordination and shaping clusters. ${ }^{8-10}$ Since their first synthesis and structural characterisation ${ }^{11}$ metallocalixarene complexes with direct coordination of the phenoxo oxygen are still relatively few comparatively with the large extent of calixarene chemistry. However their number is increasing and covers the entire periodic table ${ }^{8,9}$ with examples of complexes with $3 \mathrm{~d}^{11,12}$, $4 \mathrm{~d}^{13,14}, 5 \mathrm{~d}^{15,16}, 4 \mathrm{f}^{17,18}$ and $5 \mathrm{f}^{19-21}$ transition metal ions and different calixarene sizes.

With this in mind we recently reported on the synthesis, crystal structure and magnetism of a series of manganese(II) and iron(II) thiacalixarene complexes. ${ }^{22,23}$ Following this work we now report on a dinuclear cobalt(II) complex with $p$-tert-butylcalix[8]arene (Scheme 1) for which some complexes have been previously reported. ${ }^{19,21}$ The reason for choosing cobalt(II) lies in its well known Ising type behaviour. ${ }^{24}$ Indeed, this makes it a good candidate to instill anisotropy and several cobalt(II) polynuclear complexes have been reported that show SMMs properties. ${ }^{25-29}$

${ }^{a}$ Université Claude Bernard Lyon-1, Laboratoire des Multimatériaux et Interfaces (UMR 5615), Campus de La Doua, 69622, Villeurbanne Cedex, France.E-mail: luneau@univ-lyon1.fr; Fax: +33472431 160; Tel: +33 472 431418

${ }^{b}$ Afdeling Kwantumchemie en Fysicochemie, Katholieke Universiteit Leuven, Celestijnenlaan 200F, B-3001, Leuven, Belgium.E-mail: Liviu.Chibotaru@, chem.kuleuven.be

$\dagger$ CCDC reference number 631678. For crystallographic data in CIF or other electronic format see DOI: 10.1039/b708926k

\$ The HTML version of this article has been enhanced with colour images.

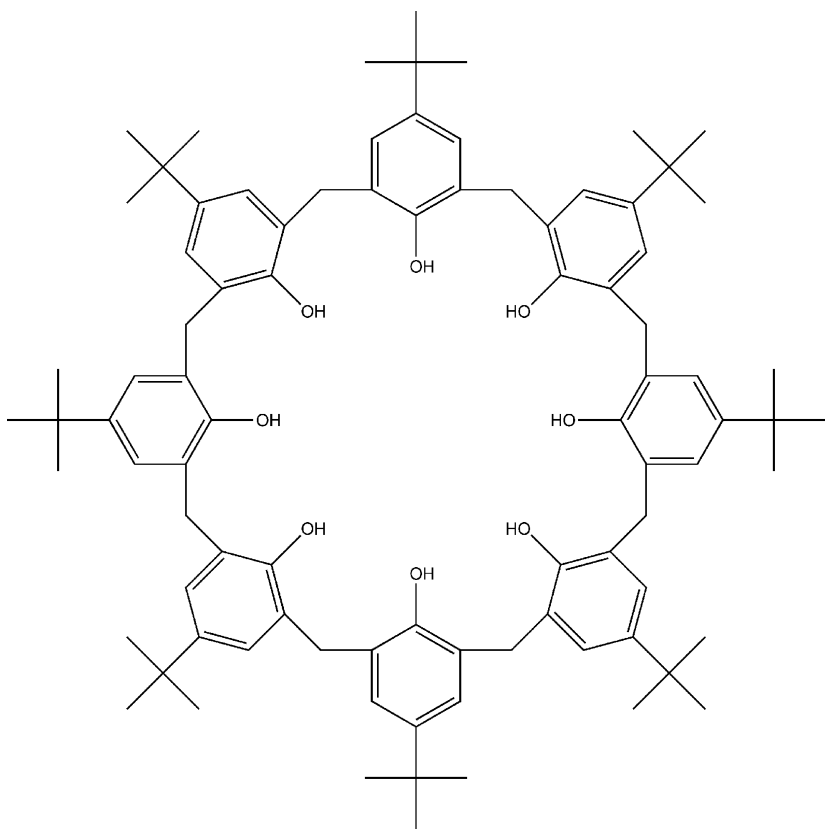

Scheme 1

\section{Results and discussion}

The compound $\left(\mathbf{1} \cdot 2 \mathrm{Et}_{3} \mathrm{NH}\right)$ was obtained in the form of blue single crystals by solvothermal synthesis in methanol when reacting $\mathrm{Co}^{\mathrm{II}}$ acetate with $p$-tert-butylcalix[8]arene (calix) and triethylamine.

\section{Description of the structure of $\left(\mathrm{Et}_{3} \mathrm{NH}\right)_{2}\left[\mathrm{Co}_{2}{ }_{2}(\text { calix })_{2}\right]\left(1 \cdot 2 \mathrm{Et}_{3} \mathrm{NH}\right)$}

The crystal structure of the compound, was established from single crystal X-ray diffraction. It exhibits a centrosymmetrical anionic complex entity $\left[\mathrm{Co}_{2}{ }_{2}(\text { calix })_{2}\right]^{2-}$ (1) formed by two cobalt(II) ions coordinated to two calix[8] arene ligands (Fig. 1a). The electronic neutrality of the compound is assumed by two triethylamonium cations (or $\mathrm{Et}_{4} \mathrm{~N}^{+}$, depending on the base used during the synthesis). These cations are located on both sides of the complex in close vicinity of the non deprotonated and non coordinated 


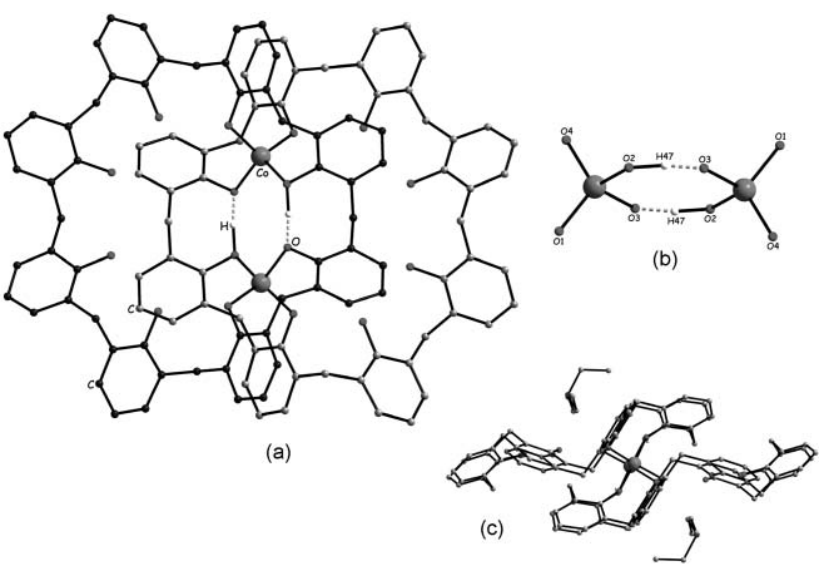

Fig. 1 (a) Molecular structure of the $\left[\mathrm{Co}_{2}{ }_{2}(\text { calix })_{2}\right]^{2-}$ complex (1) with (b) detail of the coordination mode of the $\mathrm{Co}$ (II) ions showing the hydrogen bond bridges and (c) view of the interacting triethylammonium cations. Hydrogens have been omitted for clarity.

phenol groups (Fig. 1c). The arrangement of the two calixarenes is different from the sandwich type of many metallocalixarenes but reminiscent of those found in the first iron(II) and cobalt(II) calix[4]arene complexes. ${ }^{11}$

The centrosymmetrically related cobalt(II) ions are coordinated to four phenoxo oxygen atoms provided by the two calixarene macrocycles (two oxygen from each). The oxygen environment of the cobalt(II) ions (Fig. 1b) is a slightly distorted tetrahedron which approximates $C_{2 \mathrm{v}}$ symmetry. The $\mathrm{Co}-\mathrm{O}$ bond lengths are comprised between 1.927(6) and 2.000(5) $\AA$ and the bond angles $\mathrm{O}-\mathrm{Co}-\mathrm{O}$ in the range $106.2(2)^{\circ}-116.0(2)^{\circ}$. This tetrahedral environment is in agreement with the intense blue colour of the compound.

There is no bridging phenoxo oxygen atoms in contrast with previously reported cobalt(II) calix[4]arene complexes. ${ }^{11}$ Instead close examination of the intermolecular distances reveals that two oxygen pairs are at very close distances $(\mathrm{O}-\mathrm{O}=2.405(2) \AA)$. This cannot be explained here by steric constraints of the bulky ligands which have enough room to set aside. In fact this evidences hydrogen bond bridges between the two tetrahedral $\mathrm{CoO}_{4}$ moieties (Fig. 1b) which is in total agreement with the charge balance in the compound. Indeed, as two pairs of phenoxo oxygen share protons in hydrogen bonds there are only six fully deprotonated phenol groups for a total of sixteen for the two calixarenes which fits in well with two cobalt(II) ions and two counter-cations $\left(\mathrm{Et}_{3} \mathrm{NH}^{+}\right)$. It should be stressed that the +2 oxidation state of cobalt ions was confirmed by Bond Valence Sum (BVS) calculations ${ }^{30-32}$ (calculated value: 1.94).

\section{Magnetic study}

The temperature dependence of the product of the magnetic susceptibility with temperature $(\chi T)$ for $1.2 \mathrm{Et}_{3} \mathrm{NH}$ is shown in Fig. 2. At $300 \mathrm{~K}, \chi T$ is equal to $5.33 \mathrm{~cm}^{3} \mathrm{~K} \mathrm{~mol}^{-1}$ and upon cooling it decreases down to the value of $0.52 \mathrm{~cm}^{3} \mathrm{~K} \mathrm{~mol}^{-1}$ at $2 \mathrm{~K}$. At room temperature this corresponds to an effective magnetic moment equal to $4.617 \mu_{\mathrm{B}}$ per $\mathrm{Co}(\mathrm{II})$ ion which lies in the range (4.2$4.8 \mu_{\mathrm{B}}$ ) known for most of the mononuclear Co(II) complexes in tetrahedral environment. ${ }^{33-37}$

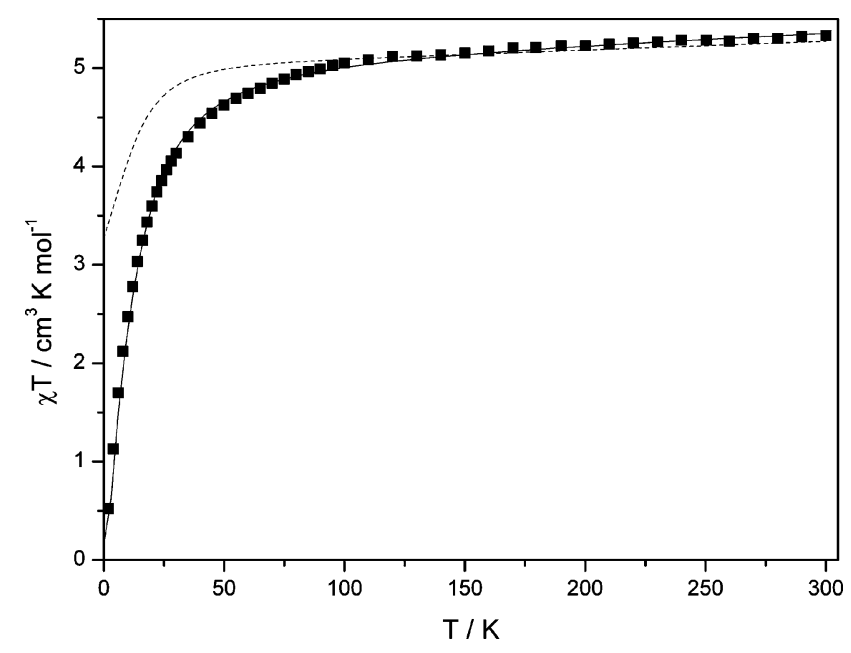

Fig. 2 Temperature dependence of the product of the molar magnetic susceptibility with temperature $(\chi T)$ for $\mathbf{1} \cdot 2 \mathrm{Et}_{4} \mathrm{~N}$. The dashed lines hold for simulation with the cobalt as magnetically isolated. The solid line holds for the simulation with values in the text when taking account of the exchange interaction between the cobalt ions.

In order to clarify the origin of different contributions to the magnetic susceptibility, $a b$ initio calculations at the CASSCF/CASPT2 level have been carried out on the mononuclear cobalt fragment of the compound. Since the two cobalt ions are related by inversion symmetry it was enough to consider only one cobalt site. The obtained Kramers doublets (Table 1) have been used for the simulation of exchange interaction between cobalt ions and of the magnetic susceptibility of the complex $\mathbf{1}$.

The calculated susceptibility corresponding to two isolated cobalt fragments was found to be very close to the experimental value at room temperature as shown in Fig. 2 (dashed line). The analysis of the electronic structure of the mononuclear fragments has shown that the first excited quartet lies at $\mathrm{ca} 3000 \mathrm{~cm}^{-1}$ while all six levels deriving from ${ }^{4} \mathrm{~T}_{1}$ and ${ }^{4} \mathrm{~T}_{2}$ lie within $\mathrm{ca} 8000 \mathrm{~cm}^{-1}$ (Table 3). The magnitude of the splitting of these orbital triplets

Table 1 Crystallographic data for $\left(\mathrm{Et}_{3} \mathrm{NH}\right)_{2}\left[\mathrm{Co}_{2}{ }_{2}(\text { calix })_{2}\right]$

\begin{tabular}{ll}
\hline Formula & $\mathrm{C}_{188} \mathrm{H}_{250} \mathrm{Co}_{2} \mathrm{~N}_{2} \mathrm{O}_{16}$ \\
\hline$M / \mathrm{g} \mathrm{mol}^{-1}$ & 2911.92 \\
Crystal system & Monoclinic \\
Space group & $P 2_{1} / n$ \\
$a / \AA$ & $14.89(1)$ \\
$b / \AA$ & $20.90(2)$ \\
$c / \AA$ & $30.87(4)$ \\
$a /^{\circ}$ & 90 \\
$\beta /{ }^{\circ}$ & $102.57(7)$ \\
$\gamma /$ & 90 \\
$V / \AA^{3}$ & $9376(16)$ \\
$Z$ & 2 \\
$T / \mathrm{K}$ & 293 \\
$d_{\text {calc }} / \mathrm{g} \mathrm{cm}^{3}$ & 1.031 \\
$\mu($ Mo-K $\alpha) / \mathrm{mm}^{-1}$ & 0.71073 \\
Measured reflections & 7626 \\
Unique Data $[I>2 \sigma I]$ & $6293\left(R_{\text {int }}=0.164\right)$ \\
$R 1$ & $0.117^{a}(0.164)^{b}$ \\
$w R 2$ & $0.113^{a}(0.155)^{b}$ \\
Goodness-of-fit & 1.1
\end{tabular}

${ }^{a}$ The value were calculated for data with $I>2 \sigma(I) .{ }^{b}$ For all data. 
is much larger than expected for $\mathrm{Co}$ (II) complexes in a slightly distorted tetrahedral environment, which at first glance is the case here if one inspects the geometry of the surrounding oxygen atoms only. Actually the symmetry of the next coordination sphere of carbon and hydrogen atoms is much lower which, given the strong interaction of oxygens with them, effectively lowers the symmetry of the ligand field felt by the cobalt ions. In order to prove this we made a series of calculations of cobalt fragments with different symmetries of nearest neighbour (oxygen) and nextnearest neighbour environments (Tables 2 and 3). We found in particular, that symmetrizing the oxygen environment to an ideal $\mathrm{T}_{\mathrm{d}} \mathrm{CoO}_{4}$ core, leaving at the same time the geometry of the next coordination sphere unchanged, results in the same splittings of the ${ }^{4} T_{1}$ and ${ }^{4} T_{2}$ terms as in the case of the experimental geometry of the fragment. This proves that the main contributions to low symmetry components of the ligand field come indeed from lowsymmetry interactions of oxygens with carbon and hydrogen atoms from the next coordination sphere. We note that such a strong effect of the geometry of the next-nearest-neighbour coordination sphere on the ligand field spectrum of Co(II) ions cannot be foreseen from a simple ligand field analysis. ${ }^{36,38}$ The last allows us to rationalise the data for complexes with monoatomic ligands like $\left[\mathrm{CoCl}_{4}\right]^{2-},{ }^{36}$ but definitely fails in the present case.

Finally, the zero-field splitting of the ground quartet ${ }^{4} \mathrm{~A}_{2}$ is obtained as $\Delta E=34 \mathrm{~cm}^{-1}$. In order to assess the nature of the lowest Kramers doublets we calculated the corresponding $g$ tensors using the recently developed ab initio methodology. ${ }^{39}$ For

Table 2 Selected bond lengths $(\AA)$ and angles $\left(^{\circ}\right)$ for $\left(\mathrm{Et}_{3} \mathrm{NH}\right)_{2}$ $\left[\mathrm{Co}_{2}{ }_{2}(\text { calix })_{2}\right]$

$\begin{array}{llll}\mathrm{Co}-\mathrm{O} 1 & 1.927(6) & \mathrm{Co}-\mathrm{O} 3 & 2.000(5) \\ \mathrm{Co}-\mathrm{O} 2 & 1.995(6) & \mathrm{Co}-\mathrm{O} 4 & 1.929(6) \\ \mathrm{Co}-\mathrm{Co}^{a} & 4.801(4) & \mathrm{O}-\mathrm{O}^{a} & 2.405(2) \\ & & & \\ \mathrm{O} 1-\mathrm{Co}-\mathrm{O} 2 & 106.4(3) & \mathrm{O} 2-\mathrm{Co}-\mathrm{O} 3 & 106.3(2) \\ \mathrm{O} 1-\mathrm{Co}-\mathrm{O} 4 & 116.0(2) & \mathrm{O} 2-\mathrm{Co}-\mathrm{O} 4 & 110.6(2) \\ \mathrm{O} 1-\mathrm{Co}-\mathrm{O} 3 & 111.0(2) & \mathrm{O} 3-\mathrm{Co}-\mathrm{O} 4 & 106.2(2)\end{array}$

${ }^{a}$ Symmetry operation: $1-x, 1-y, 1-z$. the ground and the first excited Kramers doublets we obtain the main values of the $g$ tensors $(0.82,1.76,5.24)$ and $(4.09,3.01,0.81)$, respectively. The first set of values is close to $(0,0,6)$, corresponding to the Kramers doublet of a $\pm 3 / 2$ type, while the second one is close to $(4,4,2)$, corresponding to the Kramers doublet of $\pm 1 / 2$ type. This means that the parameter of the axial component of the magnetic anisotropy is negative $(D<0)$, while the deviations in the corresponding sets of values are mostly due to the presence of the rhombic component of magnetic anisotropy, ${ }^{40}$ which is to be expected given the low symmetry of the environment of each cobalt ion. Again, the main source of the symmetry lowering comes from the next-nearest neighbour coordination sphere composed from carbon and hydrogen atoms. Moreover, the calculations in Tables 2 and 3 show that without the next-nearest neighbour coordination sphere the zero-field splitting itself would be twice smaller. This effect is analysed in the next section. Note that negative axial anisotropy parameters on individual metal sites do not imply automatically a negative sign of the axial anisotropy in the lowest exchange states of the whole complex. ${ }^{40}$ For instance, in the exchange limit ${ }^{41}$ we obtain for the ZFS parameter $D_{\mathrm{s}}$ of exchange multiplets of $\mathrm{Co}_{2}: D_{3}<0, D_{2}=0, D_{1}>0$, where $S$ is the total spin of the dinuclear unit.

As revealed by the crystal structure, the two cobalt centres in the complex (1) are not isolated but bridged though hydrogen bonds $(\mathrm{O}-\mathrm{H}-\mathrm{O})$. Therefore one may expect magnetic interaction to occur. This explains the observed discrepancy between the experimental data and the calculated susceptibility at low temperature (Fig. 2, dashed line). Due to the large value of zerofield splitting, the exchange interaction at low temperatures takes place only between ground Kramers doublets on cobalt sites and is therefore quite anisotropic. The description of this interaction requires the knowledge of nine exchange parameters, which cannot be extracted reliably from the fitting of powder susceptibility. To reduce the number of fitting parameters we use the Lines approach to treat the anisotropic exchange interaction. ${ }^{41}$ This approach begins with the isotropic exchange interactions, which would be in the absence of spin-orbit coupling on metal sites. In our case, we took into account two exchange parameters for intramolecular $(J)$ and intermolecular $\left(J^{\prime}\right)$ couplings. Diagonalizing the matrix of

Table 3 Calculations for the mononuclear fragment of the complex 1 in experimental geometry

\begin{tabular}{|c|c|c|c|c|c|c|}
\hline \multirow[b]{2}{*}{ Structure } & \multicolumn{3}{|c|}{ Energies of lowest quartets and Kramers doublets $/ \mathrm{cm}^{-1}$} & \multicolumn{3}{|c|}{ Magnetic properties/fragment } \\
\hline & $\mathrm{CASSCF}^{a}$ & $\mathrm{CASPT}^{a}$ & KD & $\mathrm{ZFS} / \mathrm{cm}^{-1}$ & $\chi T_{300 \mathrm{~K}} / \mathrm{cm}^{3} \mathrm{~K} \mathrm{~mol}^{-1}$ & $\mu_{\mathrm{eff}(300 \mathrm{~K})} / \mu_{\mathrm{B}}$ \\
\hline \multirow{13}{*}{$\mathrm{CoO}_{4} \mathrm{C}_{12} \mathrm{H}_{16} \mathrm{H}^{b}$} & & & 0.00 & & \multirow{13}{*}{2.64} & \multirow{13}{*}{4.60} \\
\hline & 0.0 & 0.0 & 34.11 & 34.11 & & \\
\hline & & & 2895.16 & & & \\
\hline & 3211.7 & 2910.2 & 3053.61 & 158.45 & & \\
\hline & & & 3954.90 & & & \\
\hline & 4245.5 & 3846.6 & 4057.14 & 102.24 & & \\
\hline & & & 5301.36 & & & \\
\hline & 4956.0 & 5353.2 & 5462.86 & 161.50 & & \\
\hline & & & 6513.01 & & & \\
\hline & 6723.7 & 6371.2 & $\begin{array}{l}6622.56 \\
8142.09\end{array}$ & 109.55 & & \\
\hline & 7569.5 & 7958.5 & 8249.81 & 107.72 & & \\
\hline & & & 8578.30 & & & \\
\hline & 7822.4 & 8024.7 & 8765.83 & 187.53 & & \\
\hline
\end{tabular}

\footnotetext{
${ }^{a}$ These energies correspond to ${ }^{4} \mathrm{~A}_{2},{ }^{4} \mathrm{~T}_{1}$ and ${ }^{4} \mathrm{~T}_{2}$, terms of $\mathrm{Co}(\mathrm{II})$ in tetrahedral environment. ${ }^{b}$ The experimental position of the atoms. These results were used for fitting of the exchange interaction between Co centres.
} 
the corresponding Heisenberg Hamiltonian, written in the basis of spin-orbit multiplets of cobalt fragments obtained from our quantum chemistry calculations, gives solutions corresponding to anisotropic exchange interactions between Kramers doublets. Both intramolecular and intermolecular interactions are found antiferromagnetic; $J=-1.75 \mathrm{~cm}^{-1}$ and $z J^{\prime}=-0.5 \mathrm{~cm}^{-1}$ ( $z$ is the number of nearest neighbours for each molecule). The simulated susceptibility is shown in Fig. 2 (solid line). We stress that all magnetic interactions on the cobalt sites are calculated from first principles, so that the only fitting parameters are $J$ and $z J^{\prime}$. In order to obtain a better agreement with experimental data, a shift of the calculated mononuclear contribution to $\chi T=0.08 \mathrm{~cm}^{3} \mathrm{~K} \mathrm{~mol}^{-1}$, correcting for errors introduced by the fragment approximation, was added.

\section{Effect of the next-nearest neighbour coordination sphere on the ZFS on cobalt sites}

In order to assess the contributions to the zero-field splitting from the low symmetry environment of carbon and hydrogen atoms surrounding the $\mathrm{CoO}_{4}$ core, we performed additional CASSCF/CASPT2 calculations. To make calculations simpler we substituted the carbon atoms by hydrogens, first ensuring that this does not lead to significant changes for the magnetic properties as compared to the previous calculations. Tables 4 and 5 present the results for mononuclear $\mathrm{Co}$ (II) model fragments. The energy levels deriving from the lowest ${ }^{4} \mathrm{~A}_{2},{ }^{4} \mathrm{~T}_{1}$ and ${ }^{4} \mathrm{~T}_{2}$ quartets of
$\mathrm{Co}(\mathrm{II})$ in a tetrahedral environment are calculated and the room temperature magnetism is simulated on this basis. A comparison of the results presented in Tables 3 and 4 show indeed that (1) the substitution of the carbon atoms by hydrogens does not much alter the magnetic susceptibility and the effective magnetic moment at room temperature. However, the ZFS seems to be much more sensitive to this substitution, therefore in the following we only judge its relative variation within the series of $\mathrm{CoO}_{4} \mathrm{H}_{n}$ model fragments.

If the hydrogens lie along the Co-O bonds (Table 4 (2)), they do not give additional low-symmetry components to the ligand field on $\mathrm{Co}(\mathrm{II})$, as was the case with the next coordination sphere of the fragment in Table 4 (1). As a result, the obtained splitting of ${ }^{4} \mathrm{~T}_{1}$ and ${ }^{4} \mathrm{~T}_{2}$ terms is several times smaller and the zero-field splitting is almost twice as low as in Table 4 (1). A comparison of the results in Tables 4 (2) and 5 (1) shows that the distortion in the $\mathrm{CoO}_{4}$ core is not essential for the magnetic moment. However, the ZFS in Table 4 (2) is completely determined by this distortion. On the other hand, the ZFS in Table 5 (2) appears entirely due to the symmetry lowering in the next-coordination sphere simulated by five hydrogens. We can see that it is twice as large as the ZFS in Table 4 (2), which arose due to the symmetry lowering in the $\mathrm{O}_{4}$ environment only. Furthermore, as the comparison with Table 4 (1) shows, the symmetrization of the $\mathrm{CoO}_{4}$ core does not reduce, but on the contrary increases the ZFS of the $\mathrm{Co}(\mathrm{II})$. This is related to the fact that the splitting of the terms ${ }^{4} \mathrm{~T}_{1}$ and ${ }^{4} \mathrm{~T}_{2}$ is slightly larger and the excitation energies are lower in Table 5 (2).

Table 4 Calculations for $\mathrm{CoO}_{4} \mathrm{H}_{n}$ model fragments with experimental geometry $\left(\mathrm{C}_{1}\right)$ of the $\mathrm{CoO}_{4}$ core

\begin{tabular}{|c|c|c|c|c|c|c|c|}
\hline \multirow[b]{2}{*}{ Nr. } & \multirow[b]{2}{*}{ Structure } & \multicolumn{3}{|c|}{ Energies of lowest quartets and Kramers doublets $/ \mathrm{cm}^{-1}$} & \multicolumn{3}{|c|}{ Magnetic properties/fragment } \\
\hline & & $\mathrm{CASSCF}^{a}$ & $\mathrm{CASPT}^{a}$ & KD & $\mathrm{ZFS} / \mathrm{cm}^{-1}$ & $\chi T_{300 \mathrm{~K}} / \mathrm{cm}^{3} \mathrm{~K} \mathrm{~mol}^{-1}$ & $\mu_{\mathrm{eff}(300 \mathrm{~K})} / \mu_{\mathrm{B}}$ \\
\hline \multirow{14}{*}{1} & \multirow{14}{*}{$\mathrm{Co}(\mathrm{OH})_{4} \mathrm{H}^{b}$} & & & 0.00 & & \multirow{14}{*}{2.70} & \multirow{14}{*}{4.65} \\
\hline & & 0.0 & 0.0 & 59.80 & $\mathbf{5 9 . 8 0}$ & & \\
\hline & & & & 2491.60 & & & \\
\hline & & 2807.9 & 2590.5 & 2678.35 & 86.75 & & \\
\hline & & & & 3599.30 & & & \\
\hline & & 3489.4 & 3462.4 & 3693.04 & 93.74 & & \\
\hline & & & & 5808.43 & & & \\
\hline & & 5250.1 & 6050.5 & 6013.63 & 205.2 & & \\
\hline & & & 61836 & $\begin{array}{l}6343.39 \\
6546.99\end{array}$ & & & \\
\hline & & 3991.0 & 6183.6 & 7984.56 & 203.6 & & \\
\hline & & 7331.6 & 7864.0 & 8203.93 & 219.37 & & \\
\hline & & & & 8561.44 & & & \\
\hline & & 7573.1 & 8165.4 & 8712.01 & 150.57 & & \\
\hline & & & & 0.00 & & & \\
\hline \multirow{11}{*}{2} & \multirow{11}{*}{$\mathrm{Co}(\mathrm{OH})_{4}{ }^{c}$} & 0.0 & 0.000 & 33.55 & 33.55 & \multirow{11}{*}{3.03} & \multirow{11}{*}{4.92} \\
\hline & & & & 2147.99 & & & \\
\hline & & 2810.6 & 2688.528 & $\begin{array}{l}2611.63 \\
283672\end{array}$ & 22509 & & \\
\hline & & & & 3098.79 & 225.07 & & \\
\hline & & 2886.5 & 2906.677 & 3165.54 & 66.75 & & \\
\hline & & & & 4059.85 & & & \\
\hline & & 4542.3 & 4236.342 & 4430.22 & 370.37 & & \\
\hline & & & & 4553.45 & & & \\
\hline & & 4662.9 & 4351.894 & 4976.33 & 422.88 & & \\
\hline & & & & 5322.65 & & & \\
\hline & & 4971.2 & 4885.503 & 5515.86 & 193.21 & & \\
\hline
\end{tabular}

${ }^{a}$ These energies correspond to ${ }^{4} \mathrm{~A}_{2},{ }^{4} \mathrm{~T}_{1}$ and ${ }^{4} \mathrm{~T}_{2}$ terms of $\mathrm{Co}(\mathrm{II})$ in tetrahedral environment. ${ }^{b}$ The $\mathrm{CoO}_{4}$ core has experimental geometry, but the carbon atoms bonded to the oxygens, were substituted by hydrogens at the same positions. ${ }^{c}$ The $\mathrm{CoO}_{4}$ core has experimental geometry, but the hydrogens were inserted along the $\mathrm{Co}-\mathrm{O}$ bond, with $0.96 \mathrm{~A} \mathrm{O}-\mathrm{H}$ bond length. 
Table 5 Calculations for $\mathrm{CoO}_{4} \mathrm{H}_{n}$ model fragments with idealized geometry $\left(\mathrm{T}_{\mathrm{d}}\right)$ of the $\mathrm{CoO}_{4}$ core

\begin{tabular}{|c|c|c|c|c|c|c|c|}
\hline \multirow[b]{2}{*}{ Nr. } & \multirow[b]{2}{*}{ Structure } & \multicolumn{3}{|c|}{ Energies of lowest quartets and Kramers doublets $/ \mathrm{cm}^{-1}$} & \multicolumn{3}{|c|}{ Magnetic properties/fragment } \\
\hline & & $\mathrm{CASSCF}^{a}$ & $\mathrm{CASPT}^{a, d}$ & $\mathrm{KD}^{e}$ & $\mathrm{ZFS} / \mathrm{cm}^{-1}$ & $\chi T_{300 \mathrm{~K}} / \mathrm{cm}^{3} \mathrm{~K} \mathrm{~mol}^{-1}$ & $\mu_{\mathrm{eff}(300 \mathrm{~K})} / \mu_{\mathrm{B}}$ \\
\hline \multirow{15}{*}{1} & \multirow{15}{*}{$\mathrm{Co}(\mathrm{OH})_{4}^{b}$} & & & 0.00 & \multirow{15}{*}{0} & \multirow{15}{*}{3.08} & \multirow{15}{*}{4.97} \\
\hline & & 0.0 & 0.0 & 0.00 & & & \\
\hline & & & & 2192.51 & & & \\
\hline & & 2371.5 & 2347.8 & 2192.51 & & & \\
\hline & & & & 2362.09 & & & \\
\hline & & 2371.5 & 2120.9 & 2681.02 & & & \\
\hline & & & & 2681.02 & & & \\
\hline & & 2371.5 & 2089.9 & 2730.65 & & & \\
\hline & & & & 3779.23 & & & \\
\hline & & 4188.1 & 4037.3 & 4258.77 & & & \\
\hline & & & & 4258.77 & & & \\
\hline & & 4188.1 & 4016.9 & 4794.25 & & & \\
\hline & & & & 4957.71 & & & \\
\hline & & 4188.1 & 3734.4 & 4957.71 & & & \\
\hline & & & & 0.00 & & & \\
\hline \multirow{12}{*}{2} & \multirow{12}{*}{$\mathrm{Co}(\mathrm{OH})_{4} \mathrm{H}^{c}$} & 0.0 & 0.0 & 70.59 & 70.59 & \multirow{12}{*}{2.75} & \multirow{12}{*}{4.69} \\
\hline & & & & 2277.68 & & & \\
\hline & & 2583.0 & 2358.2 & 2441.92 & 164.24 & & \\
\hline & & & & 3537.66 & & & \\
\hline & & 3417.5 & 3395.3 & 3622.39 & 84.73 & & \\
\hline & & & & 5790.05 & & & \\
\hline & & 5504.5 & 6296.4 & 5962.18 & 172.13 & & \\
\hline & & & & 6351.67 & & & \\
\hline & & 5836.3 & 5885.3 & $\begin{array}{l}6539.34 \\
7910.05\end{array}$ & 187.67 & & \\
\hline & & 7285.7 & 7661.3 & 8082.16 & 172.11 & & \\
\hline & & & & 8775.24 & & & \\
\hline & & 7723.3 & 8423.1 & 8882.71 & 107.47 & & \\
\hline
\end{tabular}

${ }^{a}$ These energies correspond to ${ }^{4} \mathrm{~A}_{2},{ }^{4} \mathrm{~T}_{1}$ and ${ }^{4} \mathrm{~T}_{2}$, terms of $\mathrm{Co}(\mathrm{II})$ in tetrahedral environment. ${ }^{b}$ Fully $\mathrm{T}_{\mathrm{d}}$ idealized structure. All Co-O bonds were $1.96 \mathrm{~A}$. The $\mathrm{O}-\mathrm{H}$ bonds were $0.96 \mathrm{~A} .{ }^{c}$ Only the $\mathrm{CoO}_{4}$ core has the symmetry $\mathrm{T}_{\mathrm{d}}$. All hydrogens were inserted as in the experimental structure; four of them replacing the nearest neighbour carbons; their relative angles and bond lengths were kept as in experiment. ${ }^{d}$ The splitting of the ${ }^{4} \mathrm{~T}_{1}$ and ${ }^{4} \mathrm{~T}_{2}$ terms for the $\mathrm{Co}(\mathrm{OH})_{4}$ compound is an artefact of the present version of MOLCAS/CASPT2 calculations and are within the average error of $\approx 0.2 \mathrm{eV} .46,47 e \mathrm{For}$ the $\mathrm{Co}(\mathrm{OH})_{4}$, in order to keep the symmetry, we used the CASSCF energies for the evaluation of the effects of the spin-orbit interaction. Very close results are obtained when using averaged CASPT2 energies corresponding to the ${ }^{4} T_{1}$ and ${ }^{4} T_{2}$ terms. The pairs of degenerate Kramers doublets (highlighted) correspond to $T_{8}$ and nondegenerate ones to $\mathrm{T}_{7}$ multiplets.

We can conclude that beside the first coordination sphere usually considered in the ligand field theory, also the effect of the second coordination sphere plays an important role in quantifying the ZFS on the Co(II) ions. In the case considered here the effect of the second coordination sphere proves to be twice stronger than the effect from the first coordination sphere. We expect that these conclusions will be valid also for real fragments of the Co(II) in 1 (Table 3). Namely, the main contribution to the observed ZFS $\left(34 \mathrm{~cm}^{-1}\right)$ comes from the symmetry lowering of the next coordination sphere of carbon and hydrogen atoms.

\section{Conclusions}

In conclusion, we have reported a cobalt(II) dinuclear complex with two matched $p$-tert-butylcalix[8]arene. The Co(II) ions are in tetrahedral geometry and exhibit strong magnetic anisotropy with negative axial component. We have shown that half of this anisotropy comes from the low symmetry effects of the next-nearest neighbour environments of the $\mathrm{CoO}_{4}$ core. Due to antiferromagnetic coupling between cobalt ions we do not obtain negative axial anisotropy in the lowest states of the whole $\mathrm{Co}_{2}$ complex. This however would be the case for ferromagnetic interaction between such $\mathrm{Co}$ (II) units, which may offer new prospects for the design of SMMs.

\section{Experimental}

\section{Synthesis}

All chemicals and solvents were used as received; $p$-tertButylcalix[8]arene was synthesised as reported. ${ }^{42}$

\section{Synthesis of $\left(\mathrm{Et}_{3} \mathrm{NH}\right)_{2}\left[\mathrm{Co}^{\mathrm{II}}{ }_{2}(\mathrm{calix})_{2}\right]\left(1.2 \mathrm{Et}_{3} \mathrm{NH}\right)$}

Blue single crystals suitable for X-ray crystal analysis were obtained from the reaction mixture of $p$-tert-Butylcalix[8]arene (100 mg, $0.077 \mathrm{mmol}), \mathrm{Co}\left(\mathrm{CH}_{3} \mathrm{COO}\right) 2.4 \mathrm{H} 2 \mathrm{O}$, (19.4 mg, $0.077 \mathrm{mmol})$, triethylamine $(1 \mathrm{~mL})$ and methanol $(23 \mathrm{~mL})$ in a $43 \mathrm{~mL}$ Teflon-lined autoclave at $166^{\circ} \mathrm{C}$ for 3 days. (yield: $78.4 \mathrm{mg}$, $35 \%$ ). Anal. Calcd for $\mathrm{C}_{188} \mathrm{H}_{250} \mathrm{Co}_{2} \mathrm{O}_{16} \mathrm{~N}_{2}$ : Co, 4.04; C, 77.55; $\mathrm{H}$, 8.65; N, 0.96 Found: Co, 3.92; C, 77.51; H, 8.54; N, 0.97

\section{Crystallography}

Single-crystals X-ray studies were carried out using a Nonius KappaCCD and the related analysis software. ${ }^{43}$ No absorption corrections were applied to the data sets. The structure was 
solved by direct methods using the SIR 97 program $^{44}$ combined with Fourier difference syntheses and refined against $F$ using reflections with $[I / \sigma(I)>3]$ and the CRYSTALS program. ${ }^{45}$ All atomic displacements parameters for non-hydrogen atoms have been refined with anisotropic terms. The hydrogen atoms were theoretically located on the basis of the conformation of the supporting atom. Crystallographic data and experimental details for structure analysis are given in Table 1. Selected bond lengths and angles are listed in Table 2.

CCDC reference number 631678.

For crystallographic data in CIF or other electronic format see DOI: $10.1039 / \mathrm{b} 708926 \mathrm{k}$

\section{Magnetic measurements}

The magnetic susceptibilities of the compound were measured from 2 to $300 \mathrm{~K}$ on polycrystalline samples in a PTFE capsule with an applied field of $5 \mathrm{kOe}$ using a Quantum Design SQUID magnetometer. The data were corrected for diamagnetism of the sample holder and of the constituent atoms using Pascal's constants.

\section{Computational details}

The calculations were performed with the MOLCAS 6.4 program package $^{46}$ with the basis set of the ANO-RCC DZP type. The active space included five $3 \mathrm{~d}$ orbitals of cobalt, an additional set of $4 \mathrm{~d}^{\prime}$ orbitals to take into account the double shell effect ${ }^{47}$ and one doubly occupied ligand orbital. Inclusion of the second (4d) shell is almost always necessary in order to obtain good CASSCF wave functions in cobalt complexes. ${ }^{48}$ Since we are only concerned with ligand-field levels, this active space proves to be sufficient and the inclusion of additional ligand orbitals practically does not change the results. The calculated fragment included, beside the $\mathrm{CoO} 4$ core, twelve nearest and next nearest neighbour carbon atoms, the dangling bonds of the end atoms being saturated by hydrogens (Fig. 3). The effect of spin-orbit coupling on the lowest states was taken into account by mixing ten quartet and ten lowest doublet states within the RASSI program of MOLCAS. With the obtained spin-orbit multiplets, the powder magnetic susceptibility and the $g$ tensors for the lowest Kramers doublets of isolated fragments were further evaluated using the recently developed $a b$ initio methodology. ${ }^{39}$

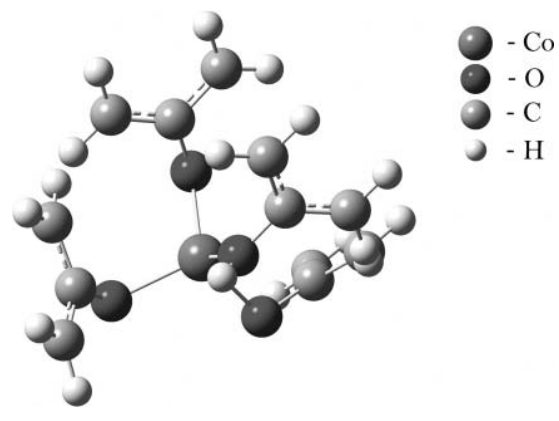

Fig. 3 The structure of the calculated fragment of $\mathbf{1}$.

\section{Acknowledgements}

The work of the French team was supported by "Région RhôneAlpes", the network of excellence MAGMANet. Magnetic measurements were performed at the CEA-Grenoble in the frame of a "Laboratoire de Recherche Conventioné du CEA" (DSM-0331). The work of the Belgian team has been supported by the Belgian Science Foundation and Flemish Government under the Concerted Action Scheme.

\section{Notes and references}

1 C. Aronica, G. Pilet, G. Chastanet, W. Wernsdorfer, J.-F. Jacquot and D. Luneau, Angew. Chem., Int. Ed., 2006, 45, 4659-4662.

2 D. Gatteschi and R. Sessoli, Angew. Chem., Int. Ed., 2003, 42, 268297.

3 S. K. Ritter, Chem. Eng. News, 2004, 82, 29-32.

4 R. Sessoli, H.-L. Tsai, A. R. Schake, S. Wang, J. B. Vincent, K. Folting, D. Gatteschi, G. Christou and D. N. Hendrickson, J. Am. Chem. Soc., 1993, 115, 1804-1816.

5 W. Wernsdorfer, Adv. Chem. Phys., 2001, 118, 99-189.

6 R. E. P. Winpenny, J. Chem. Soc., Dalton Trans., 2002, 1-10.

7 C. D. Gutsche, in Calixarenes, ed. J. F. Stoddart, The Royal Society of Chemistry, Cambridge, 1989.

8 C. Floriani and R. Floriani-Moro, Adv. Organomet. Chem., 2004, 47, $167-233$.

9 J. Harrowfield and G. Koutsantonis, in Calixarenes in the Nanoworld, ed. J. Vicens, J. Harrowfield and L. Baklouti, Springer, Netherlands, 2006.

10 N. Morohashi, F. Narumi, N. Iki, T. Hattori and S. Miyano, Chem. Rev., 2006, 106, 5291-5316.

11 M. M. Olmstead, G. Sigel, H. Hope, X. Xu and P. P. Power, J. Am. Chem. Soc., 1985, 107, 8087-8091.

12 S. G. Bott, A. W. Coleman and J. L. Atwood, J. Chem. Soc., Chem. Commun., 1986, 610-611.

13 J. A. Acho, T. Ren, J. W. Yun and S. J. Lippard, Inorg. Chem., 1995, 34, 5226-5233.

14 L. Liu, L. N. Zakharov, A. L. Rheingold, W. H. Watson and T. A. Hanna, Inorg. Chem., 2006, 45, 4247-4260.

15 D. Buccella and G. Parkin, J. Am. Chem. Soc., 2006, 128, 1635816364.

16 P. Mongrain, J. Douville, J. Gagnon, M. Drouin, A. Decken, D. Fortin and P. D. Harvey, Can. J. Chem., 2004, 82, 1452-1461.

17 J. C. Bünzli, F. Ihringer, P. Dumy, C. Sager and R. D. Rogers, J. Chem. Soc., Dalton Trans., 1998, 497-503.

18 B. M. Furphy, J. Harrowfield, D. L. Kepert, B. W. Skelton, A. H. White and F. R. Wilner, Inorg. Chem., 1987, 4231-4236.

19 J. M. Harrowfield, M. I. Ogden and A. H. White, J. Chem. Soc., Dalton Trans., 1991, 2625-2632.

20 L. Salmon, P. Thuéry and M. Ephritikhine, Chem. Commun., 2006, 856-858.

21 L. Salmon, P. Thuéry and M. Ephritikhine, Dalton Trans., 2006, 36293637.

22 C. Desroches, G. Pilet, S. A. Borshch, S. Parola and D. Luneau, Inorg. Chem., 2005, 44, 9112-9120.

23 C. Desroches, G. Pilet, P. Á. Szilágyi, G. Molnár, S. A. Borshch, A. Bousseksou, S. Parola and D. Luneau, Eur. J. Inorg. Chem., 2006, 357365.

24 R. L. Carlin, Magneto-chemistry, Springer, Berlin, 1986.

25 E. K. Brechin, O. Cador, A. Caneschi, C. Cadiou, S. G. Harris, S. Parsons, M. Vonci and R. E. P. Winpenny, Chem. Commun., 2002, $1860-1861$.

26 S. J. Langley, M. Helliwell, R. Sessoli, P. Rosa, W. Wernsdorfer and R. E. P. Winpenny, Chem. Commun., 2005, 5029-5031.

27 M. Moragues-Canovas, C. E. Talbot-Eeckelaers, L. Catala, F. Lloret, W. Wernsdorfer, E. K. Brechin and T. Mallah, Inorg. Chem., 2006, 7038-7040

28 E.-C. Yang, W. Wernsdorfer, M. Nakano, L. N. Zakharov, R. D. Sommer, A. L. Rheingold, M. Ledezma-Gairaud and G. Christou, J. Appl. Phys., 2002, 91, 7382-7384.

29 M.-H. Zeng, M.-X. Yao, H. Liang, W.-X. Zhang and X.-M. Chen, Angew. Chem., Int. Ed., 2007, 46, 1832-1835. 
30 N. E. Brese and M. O'Keeffe, Acta Crystallogr., Sect. B, 1991, B47, 192-197.

31 I. D. Brown and D. Altermatt, Acta Crystallogr., Sect. B, 1985, B41, 244-247.

32 H. H. Thorp, Inorg. Chem., 1992, 31, 1585-1588.

33 A. Bose, S. Mitra and R. Rai, Indian J. Phys., 1965, 39, 357.

34 F. A. Cotton, D. M. L. Goodgame, M. Goodgame and T. E. Haas, Inorg. Chem., 1961, 1, 565.

35 F. A. Cotton and R. H. Holm, J. Am. Chem. Soc., 1960, 82, 2979.

36 B. N. Figgis, M. Gerloch and R. Mason, Proc. R. Soc. London, Ser. A, 1964, A279, 210-228.

37 B. N. Figgis and R. S. Nyholm, J. Chem. Soc., 1958, 4190.

38 B. N. Figgis and M. A. Hitchman, Ligand Field Theory and its Applications, Wiley-VCH, New York, 2000.

39 L. F. Chibotaru and L. Ungur, unpublished.

$40 \mathrm{~A}$. Bencini and D. Gatteschi, in EPR of exchange coupled systems, Springer: Berlin, 1990.
41 M. E. Lines, A. P. Ginsberg, R. I. Martin and R. C. Sherwood, J. Chem. Phys., 1972, 57, 1-19.

42 J. H. Munch and C. D. Gutsche, Org. Synth., 1985, CV 8, 80.

43 Nonius, Kappa CCD Program Package: COLLECT, DENZO, SCALEPACK, SORTAV, (1999) Nonius B. V., Delft, The Netherlands.

44 G. Cascarano, A. Altomare, C. Giacovazzo, A. Guagliardi, A. G. G. Moliterni, D. Siliqi, M. C. Burla, G. Polidori and M. Camalli, Acta Crystallogr., Sect. A, 1996, A52, C79.

45 D. J. Watkin, C. K. Prout, J. R. Carruthers and P. W. Betteridge, CRYSTAL Issue 11, (1999) CRYSTAL Issue 11, Chemical Crystallography Laboratory, Oxford, UK.

46 G. Karlström, R. Lindh, P.-Å. Malmqvist, B. O. Roos, U. Ryde, V. Veryazov, P.-O. Widmark, M. Cossi, B. Schimmelpfennig, P. Neogrady and L. Seijo, Comput. Mater. Sci., 2003, 28, 222.

47 K. Andersson and B. O. Roos, Chem. Phys. Lett., 1992, 191, 507.

48 S. Clima, M. F. A. Hendrickx, L. F. Chibotaru, A. Soncini, V. S. Mironov and A. Ceulemans, Inorg. Chem., 2007, 46, 2682-2690. 